\title{
DELÍRIO A BICO DE PENA
}

PEN AND INK DELIRIUM

DELIRIO DIBUJADO A PLUMA

Fernando Scheibe*

RESUMO

Com base em um enunciado de Michel Foucault ("A possibilidade de falar e a possibilidade de ser louco são contemporâneas"), este artigo investiga as relaçôes entre linguagem, loucura e literatura, dialogando com autores como Clarice Lispector, Machado de Assis, Gilles Deleuze, D. H. Lawrence, Peter Stoterdjik, Michel Leiris, Jorge Luis Borges, Roland Barthes e Georges Bataille. Se a língua "é simplesmente fascista", se somos falados por ela, o delírio é inevitável e somente nos resta modulá-lo. O delírio a bico de pena é um delírio menor e, ao mesmo tempo, "histórico mundial", desenha a criança (o ser) em seu impuro devir, não busca fixá-la(o) nem impor limites. Esgarça a linguagem, constitui aquilo que Foucault, numa conversa com Duccio Trombadori, nomeava uma experiência.

Palavras-chave: Michel Foucault. Linguagem. Loucura. Literatura.

\begin{abstract}
Based on a text by Michel Foucault ("The possibility of speaking and the possibility of being crazy are contemporary"), this article is about the relations between language, madness and literature establishing a dialogue with authors such as Clarice Lispector, Machado de Assis, Gilles Deleuze, D. H. Lawrence, Peter Stoterdjik, Michel Leiris, Jorge Luis Borges, Roland Barthes and Georges Bataille. If the language "is simply fascist", if we are spoken by the language, the delirium is inevitable and all we can do is modulate it. The pen and ink delirium is a minor one and at the same time "worldly historical" delirium, it draws the child (the being) in its impure becoming, does not seek to fix it nor impose limits. It tears the language, constitutes what Foucault, in a conversation with Duccio Trombadori, named an experience.
\end{abstract}

Keywords: Michel Foucault. Language. Madness. Literature.

\footnotetext{
*Doutor em Teoria Literária pela Universidade Federal de Santa Catarina (UFSC), professor de Literatura Francesa na Universidade Federal do Amazonas (UFAM), tradutor e editor (Cultura e Barbárie Editora). Traduziu, entre outros autores, Michel Foucault, Arlette Farge, Raymond Roussel, Stéphane Mallarmé, Catherine Malabou, Moebius, Georges Didi-Huberman, Alain Badiou, Marcel Detienne e, sobretudo, Georges Bataille. Endereço: Avenida Adolfo Ducke, 405 - Coroado, Manaus-AM, Brasil. CEP: 69082-653. E-mail: fscheibe@gmail.com.
} 


\section{RESUMEN}

A partir de un enunciado de Michel Foucault ("La posibilidad de hablar y la posibilidad de ser loco son contemporáneas"), este artículo investiga las relaciones entre lenguaje, locura y literatura, dialogando con autores como Clarice Lispector, Machado de Assis, Gilles Deleuze, D. H. Lawrence, Peter Stoterdjik, Michel Leiris, Jorge Luis Borges, Roland Barthes and Georges Bataille. Si la lengua "es simplemente fascista", si somos hablados por ella, el delirio es inevitable y sólo nos queda modularlo. El delirio dibujado a pluma es un delirio menor y al mismo tiempo "histórico mundial", dibuja al niño (el ser) en su impuro devenir, no busca fijarlo ni imponer límites. Deshilacha el lenguaje, constituye aquello que Foucault, en una conversación con Duccio Trombadori, llamaba una experiencia.

Palabras clave: Michel Foucault. Lenguaje. Locura. Literatura.

A vergonha de ser um homem:

haverá razão melhor para escrever?

(Gilles Deleuze)

E por um instante a vida sadia que levara até agora pareceu-lhe um modo moralmente louco de viver.

\section{(Clarice Lispector)}

Em 1963, Michel Foucault, com a cumplicidade de Jean Doat e vários atores, produz uma série de cinco programas radiofônicos dedicados à linguagem da loucura. No último, intitulado $A$ linguagem enlouquecida, Foucault afirma:

Há, acredito, uma ideia simples e que é mais ou menos familiar a todos nós. Costuma-se pensar que o louco, pois bem, ele é louco antes mesmo de falar, e que é do fundo dessa loucura, dessa loucura originariamente muda, que ele deixa emergirem, a posteriori de certo modo, e rodopiarem ao redor dele as palavras obscuras de seu delírio como um bando de moscas cegas.

Pois bem, o que tentei nesses programas, oh, evidentemente, não demonstrar, mas simplesmente fazer escutar - e gostaria de deixar essa palavra, "escutar" [entendre], hesitar em suas significaçôes múltiplas -, o que estava tentando fazer escutar é que, entre a loucura e a linguagem, o parentesco não é simples nem de pura filiação, mas que a linguagem e a loucura estão ligadas, muito mais, num tecido emaranhado e inextricável onde a divisão, no fundo, não pode ser feita. 
Tenho a impressão, se quiserem, de que, muito fundamentalmente, em nós, a possibilidade de falar e a possibilidade de ser louco são contemporâneas, e como que gêmeas, que elas abrem, sob nossos passos, a mais perigosa, mas talvez também a mais maravilhosa ou a mais insistente de nossas liberdades.

No fundo, mesmo se todos os homens do mundo fossem razoáveis, ainda haveria, sempre, a possibilidade de atravessar o mundo de nossos signos, o mundo de nossas palavras, de nossa linguagem, de embaralhar seus sentidos mais familiares e colocar, por meio apenas do miraculoso jorrar de algumas palavras que se entrechocam, o mundo de través.

Todo homem que fala faz uso, ao menos em segredo, da absoluta liberdade de ser louco, e, inversamente, todo homem que é louco e que parece, por isso mesmo, ter se tornado absolutamente estrangeiro à língua dos homens, também este, acredito, é prisioneiro no universo fechado da linguagem (Foucault, 2016, pp. 53-54).

Falo, logo sou louco. Sou falado pela linguagem. Linguagem é loucura. A loucura não é ilha e sim continente (Assis, 2011). Ao entrar na linguagem, o animal que logo sou enlouquece. O que se considera normalidade é apenas uma modalidade dominante de loucura. Não é óbvio? Basta abrir os olhos. Pensar na própria vida. No desconcerto do mundo. Na situação política atual do Brasil. Em francês, há uma palavra muito eloquente, dessiller: "descosturar as pálpebras (de uma ave de rapina) após o adestramento". Podemos até abrir os olhos, mas já estamos adestrados. A língua "é simplesmente: fascista; pois o fascismo não é impedir de dizer, é obrigar a dizer" (Barthes, 1996, p. 13).

Invertendo os termos - ou seja, chamando de loucura justamente o estar fora da linguagem (a linguagem é tão louca que podemos usar as mesmas palavras para dizer o contrário do que dissemos - ou dizer a mesma coisa usando palavras contrárias!) -, é desse adestramento que falava Clarice Lispector numa "crônica" publicada em 1969, no Jornal do Brasil, com o título Desenhando o menino, e depois retomada no livro Felicidade clandestina como o "conto" Menino a bico de pena:

O próprio menino ajudará sua domesticação: ele é esforçado e coopera. Coopera sem saber que essa ajuda que lhe pedimos é para o seu autossacrifício. Ultimamente, ele até tem treinado muito. E assim continuará progredindo até que, pouco a pouco - pela bondade necessária com que nos salvamos - ele passará do tempo atual ao tempo cotidiano, da meditação à expressão, da existência à vida. Fazendo o grande sacrifício de não ser louco. Eu não sou louco por solidariedade com os milhares de nós que, para construir o possível, também sacrificaram a verdade que seria uma loucura (Lispector, 1981, p. 142) 
A verdade seria uma loucura. Clarice insinua até o que poderíamos chamar de um Gedankenexperiment. Como seria um mundo não humanizado, não domesticado: "Trinta mil desses meninos sentados no chão, teriam eles a chance de construir um mundo outro, um que levasse em conta a memória da atualidade absoluta a que um dia já pertencemos? A união faria a força”. Mas vocês conhecem Clarice. A conclusão é trágica. $\mathrm{O}$ menino ouve uma buzina lá fora, e sabemos que ele vai se tornar humano (louco ou seu contrário, como queiram):

Mas de repente se retesa e escuta com o corpo todo, o coração batendo pesado na barriga: fonfom!, reconhece ele de repente num grito de vitória e terror - o menino acaba de reconhecer!

- Isso mesmo! diz a mãe com orgulho, isso mesmo, meu amor, é fonfom que passou agora pela rua, vou contar para o papai que você já aprendeu, é assim mesmo que se diz: fonfom, meu amor! (Lispector, 1981, p. 143)

Após afirmar que a língua é fascista, Barthes (1996) prossegue assim: "Assim que ela é proferida, mesmo que na intimidade mais profunda do sujeito, a língua entra a serviço de um poder. Nela, infalivelmente, duas rubricas se delineiam: a autoridade da asserção, o gregarismo da repetição" (pp. 13-14).

O menino acaba de reconhecer: ferrou.

É também desse adestramento que nos fala Peter Sloterdjik ao extrair as mais catastróficas consequências de uma singela frase do escritor alemão Jean Paul em Regras para o parque humano: "Livros são cartas dirigidas a amigos, apenas mais longas" (Sloterdjik, 2000, p. 7).

\section{Mas por quê?}

Talvez encontremos uma pista nesta frase: "Recordé que es fama entre los etíopes que los monos deliberadamente no hablan para que no los obliguen a trabajar" (Borges, 1989, p. 539). Ou neste trecho de Caos em poesia, de Lawrence (2016), traduzido por Garcia:

Mas o homem não pode viver no caos. Os animais podem. Para o animal, tudo é caos, há somente alguns poucos aspectos e movimentos recorrentes dentro de ondulações vibratórias. E o animal está contente. Mas o homem, não. $\mathrm{O}$ homem precisa embrulhar a si numa visão, fazer uma casa com uma forma visível e com estabilidade, com fixidez. Em seu terror pelo caos, o homem começa armando um guarda-sol entre ele próprio e aquele vórtice intenso na sua duração sem fim caos. Então ele colore o lado interno de seu guardasol, imitando o firmamento. Então ele desfila por aí, vive e morre debaixo de seu guarda-sol. 
Legado a seus descendentes, o guarda-sol torna-se uma cúpulacapela, uma casaforte, uma câmara mortuária, e os homens começam a sentir, finalmente, que alguma coisa está errada (p. 22).

Ou, ainda, no pensamento de Bataille (citado por Scheibe, 2013):

Para Bataille, o ser humano é um ser descontínuo. Nasce só. Morre só. O paradoxo é que se, por um lado, queremos sempre conservar essa descontinuidade (tememos a morte), por outro, sentimos falta da continuidade perdida ao nos percebermos como "indivíduos" (desejamos a morte). O erotismo é a dança, propriamente humana, que se dá entre estes dois polos: o do interdito e o da transgressão.

O interdito, a proibição, éo mundo do trabalho, da identidade, da conservação, da descontinuidade. Ao começar a trabalhar, o homem recuou do movimento vertiginoso, violento, do constante nascer/morrer da natureza. Trabalhar é subordinar o instante-já, o momento presente, a um resultado futuro. Fabricar para depois usar, plantar para depois colher, criar para depois comer... Notese que é assim também que se estabelece a noção de identidade: supõe-se talvez erroneamente - que aquele que está trabalhando é o mesmo que depois usufruirá. A contraface disso: também sou eu que estou trabalhando o mesmo que morrerá e apodrecerá. A "invenção da morte", que se manifesta na prática do sepultamento (ou da cremação, ou da devoração ritual do cadáver: algum tipo de deferência para com o corpo do morto), é contemporânea da invenção do trabalho.

O interdito, o trabalho torna o homem humano. Mas também faz dele uma coisa. Se o aceitamos inteiramente, nos tornamos simples coisas úteis, mas, no final das contas, cabe perguntar: úteis para quê? Deparamo-nos, assim, com o que Bataille chamava "paradoxo da utilidade absoluta": descartada a existência de um patrão absoluto - Deus - para que pode servir tudo aquilo que consideramos útil? Para o inútil, para a transgressão.

A transgressão do humano - do interdito, da lógica do trabalho (que é também a da linguagem) - é o ápice do humano. $\mathrm{O}$ erotismo é a experiência interior dessa transgressão, desse ápice, desse pas au-delà: "A experiência interior do homem é dada no instante em que, quebrando a crisálida, ele tem a consciência de dilacerar a si mesmo, não a resistência oposta de fora" (pp. 16-17).

Desponta aqui uma outra maneira de entender a loucura, ou seja, a humanidade, ou seja, a linguagem: a loucura do ser humano seria a loucura de uma mola. $\mathrm{O}$ humano recua para melhor saltar. Trabalha para melhor gastar. Fala para melhor calar, rir ou urrar? Será que a humanidade atual é uma mola emperrada? Pra ser bem sincero, pego-me desejando a mais completa inconsciência. Pulsão de morte? Niilismo? Preciso ler o livro de Peter [...] (Pelbart, 2013). 
Por falar em Peter, sigo adiante citando um trecho de sua tradução, ligeiramente modificada, de $A$ literatura e a vida:

A literatura é delírio, mas o delírio não tem a ver com o pai-mãe: não há delírio que não passe pelos povos, pelas raças e tribos, e que não assombre a história universal. Todo delírio e histórico-mundial, "deslocamento de raças e de continentes". A literatura é delírio e, sendo assim, seu destino se decide entre dois polos do delírio. O delírio e uma doença, a doença por excelência a cada vez que erige uma raça pretensamente pura e dominante. Mas é a medida da saúde quando invoca essa raça bastarda oprimida que não para de se agitar sob as dominações, de resistir a tudo o que esmaga e aprisiona e de, como processo, se desenhar em filigrana na literatura. Também aí um estado doentio ameaça sempre interromper o processo ou o devir; e voltamos a encontrar a mesma ambiguidade que se nota no caso da saúde e do atletismo, o risco constante de que um delírio de dominação se misture ao delírio bastardo e arraste a literatura a um fascismo larvado, a doença contra a qual ela luta, pronta para diagnosticá-la em si mesma e para lutar contra si mesma. Fim último da literatura: separar no delírio essa criação de uma saúde, ou essa invenção de um povo, isto é, uma possibilidade de vida. Escrever por esse povo que falta... ("por" significa "em intenção de" e não "em lugar de") (Deleuze, 1997, p. 15).

Juntam-se assim as duas metades que compõem o simbólico (Foucault, 2002) título deste artigo.

Se a língua é fascista, se o logos é nossa prisão, a literatura, mais do que um corpus, é um gesto (um processo) de esgarçar os limites dessa prisão.

Volto a Lawrence (2016):

E quanto aos poetas neste nó? Eles revelam o desejo interno da humanidade. O que revelam? Eles mostram o desejo por caos e, ao mesmo tempo, o medo do caos. O desejo pelo caos é a respiração de sua poesia. O medo do caos está no desfile de formas e técnicas. Poesia, dizem, é feita de palavras. Então, sopram-se bolhas de som e imagem, que, em seguida, irão estourar com a respiração que anela pelo exato caos que a preenche. Os poetastros podem fazer bolinhas bonitas e brilhantes para a árvore de natal, as quais nunca se rompem, porque não há sopro dentro delas: elas permanecem até o momento em que as deixamos cair (p. 36).

A Deleuze: "A escritura não tem outro objetivo: o vento" (Deleuze \& Parnet, 1998, p. 61)

E a Bataille (2016): "A diferença entre experiência interior e filosofia reside principalmente no fato de que, na experiência, o enunciado não é nada, apenas um meio e, até, tanto quanto um meio, um obstáculo; o que conta não é mais o enunciado do vento, é o vento" (p. 45).

Dizem que, lá pro fim dos anos 1960, Foucault se desinteressou pela literatura. Eu diria antes que Foucault sempre esteve atento ao vento. E que, se consideramos a literatura como uma tauromaquia (Leiris, 2003), ou seja, como constante exposição ao perigo de que o chifre do real arranque nossas vísceras, 
nada mais literário que seus sucessivos deslocamentos. Ouçamos o que ele dizia, já em fins de 1978, a Duccio Trombadori:

- Não me considero como um filósofo. O que faço não é nem uma maneira de fazer filosofia nem de sugerir aos outros que não façam. Os autores mais importantes que, não diria que me formaram, mas que permitiram que eu me desviasse em relação a minha formação universitária, foram caras como Bataille, Nietzsche, Blanchot, Klossowski, que não eram filósofos no sentido institucional do termo, e um certo número de experiências pessoais, é claro. $\mathrm{O}$ que mais mexeu comigo e me fascinou neles, e que lhes deu essa importância capital pra mim, é que o problema deles não era a construção de um sistema e sim de uma experiência pessoal. Na universidade, em contrapartida, eu tinha sido treinado, formado, impelido ao aprendizado dessas grandes maquinarias filosóficas que se chamavam hegelianismo, fenomenologia $[\ldots]$

- Você fala da fenomenologia, mas todo o pensamento fenomenológico repousa sobre o problema da experiência e se apoia nela para traçar seu próprio horizonte teórico. Em que sentido então você se distingue dela?

- A experiência do fenomenólogo é, no fundo, uma certa maneira de lançar um olhar reflexivo sobre um objeto qualquer da vivência, sobre o cotidiano em sua forma transitória para apreender suas significações. Para Nietzsche, Bataille, Blanchot, ao contrário, a experiência é tentar chegar a um certo ponto da vida que esteja o mais perto possível do invivível. O que é requisitado é o máximo de intensidade e, ao mesmo tempo, de impossibilidade. $\mathrm{O}$ trabalho fenomenológico, ao contrário, consiste em desdobrar todo o campo de possibilidades ligadas à experiência cotidiana. -

Além disso, a fenomenologia busca recuperar a significação da experiência cotidiana para encontrar em que o sujeito que sou é efetivamente fundador, em suas funçōes transcendentais, dessa experiência e dessas significaçōes. Em contrapartida, a experiência em Nietzsche, Blanchot, Bataille tem por função arrancar o sujeito a si mesmo, fazer com que ele não seja mais ele mesmo ou que seja levado a sua aniquilação ou a sua dissolução. É um empreendimento de dessubjetivação.

A ideia de uma experiência limite, que arranca o sujeito a si mesmo, eis o que foi importante para mim na leitura de Nietzsche, de Bataille, de Blanchot, e que fez com que, por mais enfadonhos e eruditos que os meus livros sejam, eu os tenha sempre concebido como experiências diretas visando a me arrancar de mim mesmo, a me impedir de ser o mesmo (Foucault, 1980).

A loucura de Foucault (sua verdade) é a dessa busca que o fez viver tão intensamente e morrer tão cedo. 


\section{REFERÊNCIAS}

Assis, J. M. M. (2011). O alienista. In A. J. M. Machado, Papéis avulsos. São Paulo: Companhia das Letras.

Barthes, R. (1996). Aula. L. Perrone-Moysés (Trad.). Campinas: Cultrix.

Bataille, G. (2016). A experiência interior. F. Scheibe (Trad.). Belo Horizonte: Autêntica.

Borges, J. L. (1989). Obras completas (Vol. 1). Barcelona: Emecé.

Deleuze, G. (1997). A literatura e a vida. In G. Deleuze. Critica e clínica. P. P. Pelbart (Trad.). São Paulo: 34 Letras.

Deleuze, G. \& Parnet, C. (1998). Diálogos. E. A. Ribeiro (Trad.). São Paulo: Escuta.

Foucault, M. (1980, janeiro-março). Conversazione com Michel Foucault. Il Contributo, ano 4, 1, 23-84.

Foucault, M. (2002). A verdade e as formas jurídicas. (3a ed., R. Machado \& E. J. Morais, Trad.). Rio de Janeiro: Nau.

Foucault, M. (2016). A grande estrangeira. F. Scheibe (Trad.). Belo Horizonte: Autêntica.

Lawrence, D. H. (2016). Caos em poesia. W. Garcia (Trad.). Florianópolis: Cultura e Barbárie.

Leiris, M. (2003). A idade viril precedido de Da literatura como tauromaquia. P. Neves (Trad.). São Paulo: Cosac Naify.

Lispector, C. (1981). Menino a bico de pena. In C. Lispector. Felicidade clandestina. Rio de Janeiro: Nova Fronteira.

Pelbart, P. P. (2013). O avesso do niilismo: cartografias do esgotamento. São Paulo: $\mathrm{N}-1$.

Scheibe, F. (2013). Apresentação do tradutor. In G. Bataille. O erotismo. Belo Horizonte: Autêntica.

Sloterdjik, P. (2000). Regras para o parque humano. J. O. A. Marques (Trad.). São Paulo: Estação Liberdade. 